\title{
VEHICLE/TRACK INTERACTION UNDER THE CONDITIONS OF HIGH SPEED RAILWAY OPERATION
}

\author{
JiŘÍ ŠlapÁK*, TOMÁŠ MiCHÁleK \\ University of Pardubice, Faculty of Transport Engineering, Department of Transport Means and Dignostics, \\ Studentská 95, 532 10 Pardubice, Czech Republic \\ * corresponding author: jiri.slapak@upce.cz
}

\begin{abstract}
This paper deals with the issue of dynamic effects of a high-speed railway vehicle on the track. Some aspects of vehicle/track interaction at higher speeds are described. In this context, a multi-body model of high-speed railway vehicle was created and several simulation scenarios were performed with this model. Furthermore, the simulations were evaluated with a focus on selected characteristics of the vehicle/track interaction.
\end{abstract}

KEYWORDS: Vehicle/track interaction, dynamic wheel force, damaging effect, multi-body simulation.

\section{INTRODUCTION}

High speed railway operation makes demands on all structural subsystems (infrastructure, energy, rolling stock, control command and signaling) of the railway system which have to meet relevant requirements of the technical specifications for interoperability (TSIs). In the field of vehicle/track interaction, these requirements are connected especially with (vertical) wheel forces and vehicle running stability, i.e. with straining of the track.

This paper is focused on the influence of vehicle speed on selected characteristics of the vehicle/track interaction representing damaging effects of the vehicle on the track. By means of multi-body simulations of vehicle running performance, a quantification of these damaging effects can be performed.

\section{VEHICLE/TRACK INTERACTION AT HIGHER SPEEDS}

During the run of a railway vehicle on a real track, track irregularities represent a kinematic excitation of the mechanical system of the vehicle. A direct consequence of this effect is an oscillation of the wheel forces (acting between individual wheels and rails in vertical direction) around their static values during the run. The static values of the wheel forces are given by the relevant axle load; amplitudes of the oscillations are influenced with the unsprung masses, vehicle speed and the track irregularities [1. In order to minimize the dynamic interaction between the vehicle and the track in vertical direction, the axle load of the highspeed vehicles is limited. According to the relevant TSIs, the maximum axle load of the vehicles intended for running at speed $250 \mathrm{~km} / \mathrm{h}$ and more is $17 \mathrm{t}$ [2]; locomotives with the axle load up to $22.5 \mathrm{t}$ can be used up to $230 \mathrm{~km} / \mathrm{h}$. A minimization of dynamic components of the (vertical) wheel force interaction can be reached practically only by the reduction of unsprung masses in the vehicle running gear.
Another aspect of the vehicle/track interaction the running stability - is related to the safety as well as running comfort. Safeguarding of a stable run of the vehicle under all relevant conditions (equivalent conicity) is a necessary condition for the high speed operation. The technical solutions used to improve running stability (very rigid wheelset guiding, effective damping of bogie yaw motion etc.) usually lead to increased damaging effects of the vehicle run on rails in curves. However, the running stability is not the object of this paper.

Guiding forces and related frictional work in wheel/rail contact (creeps and tangential creep wheel forces) cause the damaging effects of rails in curve. In addition to the technical solution of the vehicle, the damaging effect also depends on the operating conditions of the vehicle (radii of curves, vehicle speed).

\section{Multi-Body Simulations}

For prediction of railway vehicle behaviour under the specific operation conditions and for the first consideration about vehicle/track interaction, a multi-body simulations of railway vehicles can be used. In this case, the high speed operation is the specific condition. The one of the advantage of simulations is that it can predict vehicles running behaviour if the running tests on a real railway vehicle can't be performed.

The suitable model of railway vehicle must be created for multi-body simulations. Also the simulation scenarios (track properties) must be designed. The used model and scenarios of simulations correspond to the high speed railway conditions.

The multi-body simulations can be performed in a various commercial software, for example ADAMS/Rail, VAMPIRE, SIMPACK. Of course, it is possible to create own simulation program. For purpose of this paper, the multi-body simulations of railway vehicle running were performed using the simulation software SIMPACK 9.9.2. 


\subsection{MUlTi-BODY MODEL OF RAILWAY VEHICLE}

For the purpose of this work, a multi-body model of a high-speed railway vehicle was created. This model represents one passenger coach. Because the parameters of high-speed vehicles are different than parameters of conventional vehicles operating in the Czech Republic, the multi-body model represents Chinese Railway High-speed (CRH) vehicle, which is described in 3]. Selected fundamental parameters of the multi-body model are listed in Table 1.

\begin{tabular}{lcc}
\hline Parameter & Value & Unit \\
\hline Mass of the carbody & 35880 & $\mathrm{~kg}$ \\
\hline Mass of the bogie frame & 3300 & $\mathrm{~kg}$ \\
\hline Mass of the wheelset & 1751.8 & $\mathrm{~kg}$ \\
\hline Bogie distance & 17.5 & $\mathrm{~m}$ \\
\hline Wheelset distance & 2.5 & $\mathrm{~m}$ \\
\hline $\begin{array}{l}\text { Vertical stiffness of the } \\
\text { primary spring (per wheel) }\end{array}$ & 1.176 & $\mathrm{kN} / \mathrm{mm}$ \\
\hline $\begin{array}{l}\text { Vertical stiffness of the } \\
\begin{array}{l}\text { secondary spring } \\
\text { (per side of bogie) }\end{array}\end{array}$ & \\
\hline
\end{tabular}

TABLE 1. Fundamental parameters of the multi-body model of the railway vehicle.

The wheel profile ORE S1002 and the rail profile $60 \mathrm{E} 1$ were used. The rail inclination of 1:20 was considered to achieve better running stability of the vehicle model. For wheel/rail contact modeling, the method FASTSIM and the friction coefficient value $f=0.3$ was selected. The reference track irregularities were used for all multi-body simulations. Because of realistic modeling of the track, the model of elastic track foundation was used in order to describe the railway sleepers and elastic joint between a sleeper and solid ground.

\subsection{Simulation SCEnARIOS}

For the purpose of this paper, four scenarios of simulations were designed. These scenarios represent typical operating conditions on high speed railway lines.

In all senarios, the 2200 meters long track sections were created. First 200 meters long part of each track section was considered without irregularities. Then the reference track irregularities begin and continue until the end of track section.

\subsubsection{INFLUENCE OF RUNNING ON A STRAIGHT TRACK}

In the first scenario, each simulation of railway vehicle running was performed on the same straight track but at a different vehicle speed. Specifically, the vehicle speeds are given in Table 2 for this scenario. The minimum speed $(160 \mathrm{~km} / \mathrm{h})$ was chosen in order to perform simulations at a vehicle speed higher than the czech conventional track lines allow. The maximum vehicle speed $(350 \mathrm{~km} / \mathrm{h})$ was chosen with regard to the assumption of a maximal operation speed of $320 \mathrm{~km} / \mathrm{h}$. For vehicle speed higher than $300 \mathrm{~km} / \mathrm{h}$, the speed of the test run of railway vehicle must be increased by $30 \mathrm{~km} / \mathrm{h}$ according to [5].

\begin{tabular}{llllllll}
\hline \multicolumn{7}{c}{$\mathbf{V}[\mathbf{k m} / \mathbf{h}]$} \\
\hline 160 & 200 & 225 & 250 & 275 & 300 & 320 & 350 \\
\hline
\end{tabular}

TABLE 2. Vehicle speed parameters $V$ of the first simulation scenario.

\subsubsection{INFLUENCE OF CANT DEFICIENCY}

The second scenario deals with railway vehicle running on curved tracks. The same constant radius of curve was set for all the tracks. For high speed railway vehicle operations, the large radii of curves are typical. The value of curve radius $R=4320 \mathrm{~m}$ was selected for these simulations. But the vehicle speed was changing for each simulation of running vehicle, it means that a cant deficiency $I$ was changing too. The cant deficiency $I$ was calculated according to the stated conditions and Equation 1. For this scenario, the simulation parameters are listed in Table 3, where $D$ is the cant.

$$
I=11,8 \cdot \frac{V^{2}}{R}-D
$$

\begin{tabular}{cccc}
\hline $\mathbf{D}[\mathbf{m m}]$ & $\mathbf{I}[\mathbf{m m}]$ & $\mathbf{R}[\mathbf{m}]$ & $\mathbf{V}[\mathbf{k m} / \mathbf{h}]$ \\
\hline 180 & -110.1 & 4230 & 160 \\
\hline 180 & -81.4 & 4230 & 190 \\
\hline 180 & -70.7 & 4230 & 200 \\
\hline 180 & -41.7 & 4230 & 225 \\
\hline 180 & -9.3 & 4230 & 250 \\
\hline 180 & 26.6 & 4230 & 275 \\
\hline 180 & 65.8 & 4230 & 300 \\
\hline 180 & 99.7 & 4230 & 320 \\
\hline 180 & 154.6 & 4230 & 350
\end{tabular}

TABle 3 . The parameters of cant $D$, cant deficiency $I$, curve radius $R$ and vehicle speed $V$ of the second simulation scenario.

\subsubsection{INFLUENCE OF CURVE RADIUS}

Another scenario is based on a constant value of cant deficiency $I=100 \mathrm{~mm}$. Here the radii of curves were changing. For each case of curve radius $R$, the vehicle speed $V$ was calculated according to Equation 2 and the values of cant $D$ and cant deficiency $I$ were constant. The simulation parameters are listed in Table 4 for this scenario.

$$
V=\sqrt{(D+I) \cdot \frac{R}{11,8}}
$$




\begin{tabular}{cccc}
\hline $\mathbf{D}[\mathbf{m m}]$ & $\mathbf{I}[\mathbf{m m}]$ & $\mathbf{R}[\mathbf{m}]$ & $\mathbf{V}[\mathbf{k m} / \mathbf{h}]$ \\
\hline 180 & 100 & 3800 & 300.3 \\
\hline 180 & 100 & 4100 & 311.9 \\
\hline 180 & 100 & 4400 & 323.1 \\
\hline 180 & 100 & 4700 & 334.0 \\
\hline 180 & 100 & 5000 & 344.5
\end{tabular}

TABLE 4. The parameters of cant $D$, cant deficiency $I$, curve radius $R$ and vehicle speed $V$ of the third simulation scenario.

\subsubsection{INFLUENCE OF SPECIFIC CONDITIONS AROUND THE SPEED LIMIT OF $300 \mathrm{KM} / \mathrm{H}$}

The last scenario of simulations was focused to show one of the specific condition of high speed railway operation according to TSI 2]. In the TSI, there is the table with cant deficiency conditions for high speed vehicle operation. The table says that the maximum value of the cant deficiency is $I=153 \mathrm{~mm}$ for vehicle speed $V \leq 300 \mathrm{~km} / \mathrm{h}$. However for vehicle speed $V>300 \mathrm{~km} / \mathrm{h}$, the maximum value of the cant deficiency $I=100 \mathrm{~mm}$ is defined. These conditions apply to railway vehicles and locomotives for passenger transport.

So the value of cant deficiency is abruptly changed at this specified vehicle speed. The aim of this scenario is to investigate what happens around this vehicle speed. The radii of curves were defined in order to set the vehicle speed around the value $V=300 \mathrm{~km} / \mathrm{h}$. For this scenario, the Equation 2 was used to calcuate the vehicle speed and the simulation parameters are listed in Table 5 .

\begin{tabular}{cccc}
\hline $\mathbf{D}[\mathbf{m m}]$ & $\mathbf{I}[\mathbf{m m}]$ & $\mathbf{R}[\mathbf{m}]$ & $\mathbf{V}[\mathbf{k m} / \mathbf{h}]$ \\
\hline 180 & 153 & 2800 & 281.1 \\
\hline 180 & 153 & 3000 & 291.0 \\
\hline 180 & 153 & 3150 & 298.2 \\
\hline 180 & 100 & 3800 & 300.3 \\
\hline 180 & 100 & 4000 & 308.1 \\
\hline 180 & 100 & 4200 & 315.7
\end{tabular}

TABle 5. The parameters of cant $D$, cant deficiency $I$, curve radius $R$ and vehicle speed $V$ of the fourth simulation scenario.

\section{Simulation Results}

The multi-body simulations of running vehicle were performed according to the conditions for each scenario. Time records of quantities characterizing the dynamic effects of a running vehicle on the track were exported for each multi-body simulation.

Then the exported data were processed in Matlab software.

Figure 1 shows the marks of individual wheels of the vehicle model. The letters $L$ and $R$ indicate the left and right sides of the vehicle.

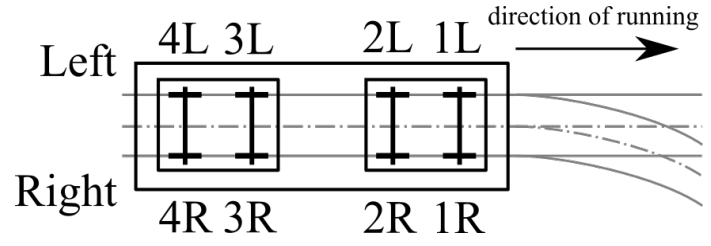

Figure 1. Selected marking of individual wheels of the vehicle model.

\subsection{Results FROM STRAight TRACK}

The vertical wheel forces $Q$ were monitored in all cases of straight track simulations. The mean value of vertical wheel force represents the static vertical wheel force $Q_{\text {stat }}$, its value does not depend on vehicle speed. In order to capture the dynamic effect of this force, it is necessary to focus on the oscillation around the mean value, i.e. the static value of the vertical wheel force $Q_{\text {stat }}$. The oscillating part of vertical wheel force is marked as $\Delta Q$. For the purpose of this paper, the force $\Delta Q$ is called the partial dynamic wheel force. The dynamic wheel force $Q_{d y n}$ is expressed in Equation 3.

$$
Q_{d y n}=Q_{\text {stat }}+\Delta Q
$$

This means that the recorded vertical wheel forces were the dynamic wheel forces $Q_{d y n}$. The 99.85th percentile of the time record of vertical wheel force was used to evaluate the dynamic wheel force $Q_{d y n}$. This evaluation was used for simulations performed at different vehicle speeds (Table 2). The dependence between vehicle speed $V$ and mean dynamic wheel force $Q_{d y n \_m}$ is shown in Figure 2. The mean dynamic wheel force $Q_{d y n \_m}$ was calculated as mean value of dynamic wheel forces $Q_{d y n}$ on all wheels of the vehicle. This calculation was performed for each value of vehicle speed.

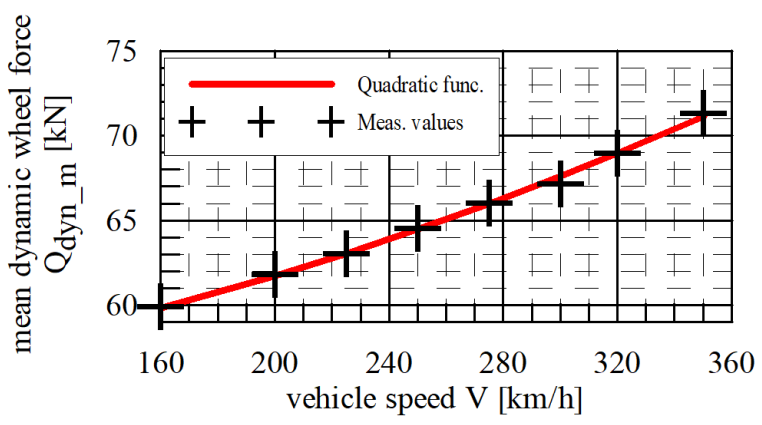

Figure 2. Influence of vehicle speed $V$ on dynamic wheel force $Q_{d y n}$ under the conditions of straight track.

Figure 2 shows that the mean dynamic wheel force $Q_{d y n \_m}$ progressively increases with the vehicle speed $V$. However, according to the British standard GM/TT0088 [1], the dynamic wheel force is linearly dependent on the vehicle speed. The standard defines a force called $P 2$, which represents the dynamic wheel force and it is described by the Equation 4 .

$$
P 2=Q_{\text {stat }}+a \cdot V
$$




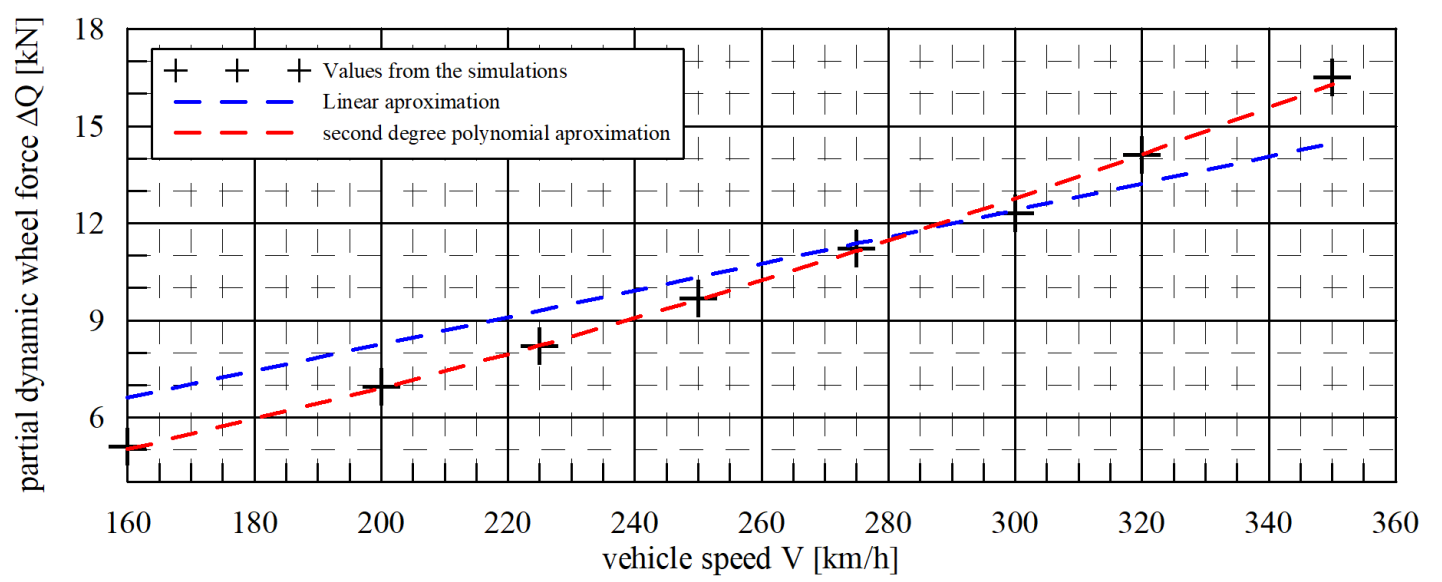

FiguRE 3. Influence of vehicle speed $V$ on partial dynamic wheel force $\Delta Q$ under the conditions of the straight track.

The parameter $a$ in Equation 4 depends on the unsprung mass in running gear of the vehicle [1].

The second part of Equation $4(a \cdot V)$ corresponds to the partial dynamic wheel force $\Delta Q$, it means that the partial dynamic wheel force is a function of the vehicle speed. The influence of vehicle speed $V$ on partial dynamic wheel force $\Delta Q$ is shown in Figure 3 .

The linear approximation of the dependence of the partial dynamic wheel force on the vehicle speed shows the coefficient of determination $R^{2}=0.895$. The linear function is shown in Figure 3 by blue dashed line. The second degree polynomial (quadratic) approximation gives a better result. There is a coefficient of determination $R^{2}=0.997$. This means that the second degree polynomial is a better function for approximating the dependence of the dynamic wheel force on the vehicle speed for high speed railway operation.

$$
\Delta Q=0.0008 \cdot V^{2}+0.01855 \cdot V
$$

Equation 5 is the polynomial approximation, which is shown in Figure 3 by red dashed line. The parameters of this equation are specific to the simulation conditions. For example, the parameters of Equation 5 can be changed by various track irregularities.

\subsection{ReSUlts FROM CURVED TRACKS}

The situation of vehicle/track interaction in curved track is different. The track is significantly loaded in the lateral direction due to the effect of centrifugal (inertia) force. The track leads the railway vehicle through the curve. In addition to the force interaction, there is a sliding movement in the wheel/rail contact.

A special characteristic called Wear Number $W N$ is used to describe the effects of a railway vehicle on a curved track. In general, the Wear Number represents a specific friction work and it is used to evaluation of rail wear on a curved track, for example [4]. The Wear Number is defined by tangential contact forces $T$ and creeps $\gamma$ in the longitudinal $(x)$ and lateral (y) directions. The formula for calculating the Wear
Number is given by Equation 6 .

$$
W N=\left|T_{x} \cdot \gamma_{x}\right|+\left|T_{y} \cdot \gamma_{y}\right|
$$

The mean value of Wear Number was evaluated. To evaluate the Wear Number, the only part of the track where the whole vehicle was in the curve was selected. This part of the track starts at $700 \mathrm{~m}$ and ends at $1700 \mathrm{~m}$, so only 1000 meters of the track were evaluated.

\subsubsection{INFLUENCE OF CANT DEFICIENCY}

In the first case of a multi-body simulation of railway vehicle in a curved track, the curve radius $R$ and the value of cant $D$ were constant. The vehicle speed $V$ was increased from $160 \mathrm{~km} / \mathrm{h}$ to $350 \mathrm{~km} / \mathrm{h}$ in individual steps, as well as the cant deficiency $I$ (according to Equation 1). The simulation conditions are described in Section 3.2.2.

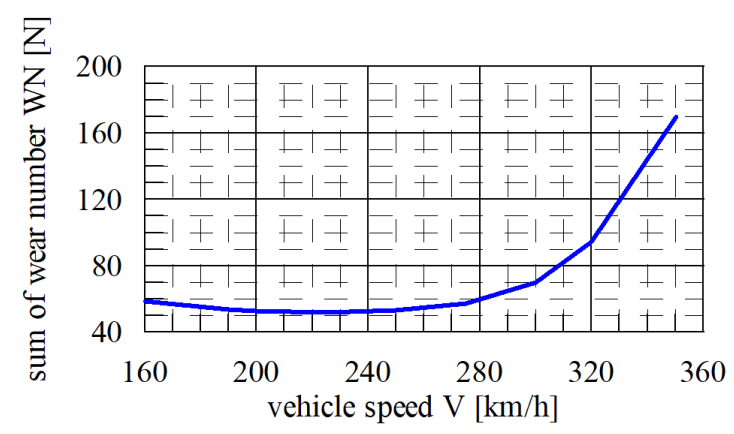

Figure 4. Dependence of the sum of the Wear Number $W N$ values of all vehicle wheels on vehicle speed $V$ at constant track parameters (cant, curve radius).

Firstly, for a very simplified introduction to this scenario, the dependence of the sum of the Wear Number $W N$ values of all vehicle wheels on vehicle speed $V$ is shown in Figure 4. The figure shows that the Wear Number value increases progressively with the vehicle speed under conditions of constant curve radius. A very similar dependence is shown in Figure 6. This figure shows the effect of the cant deficiency 


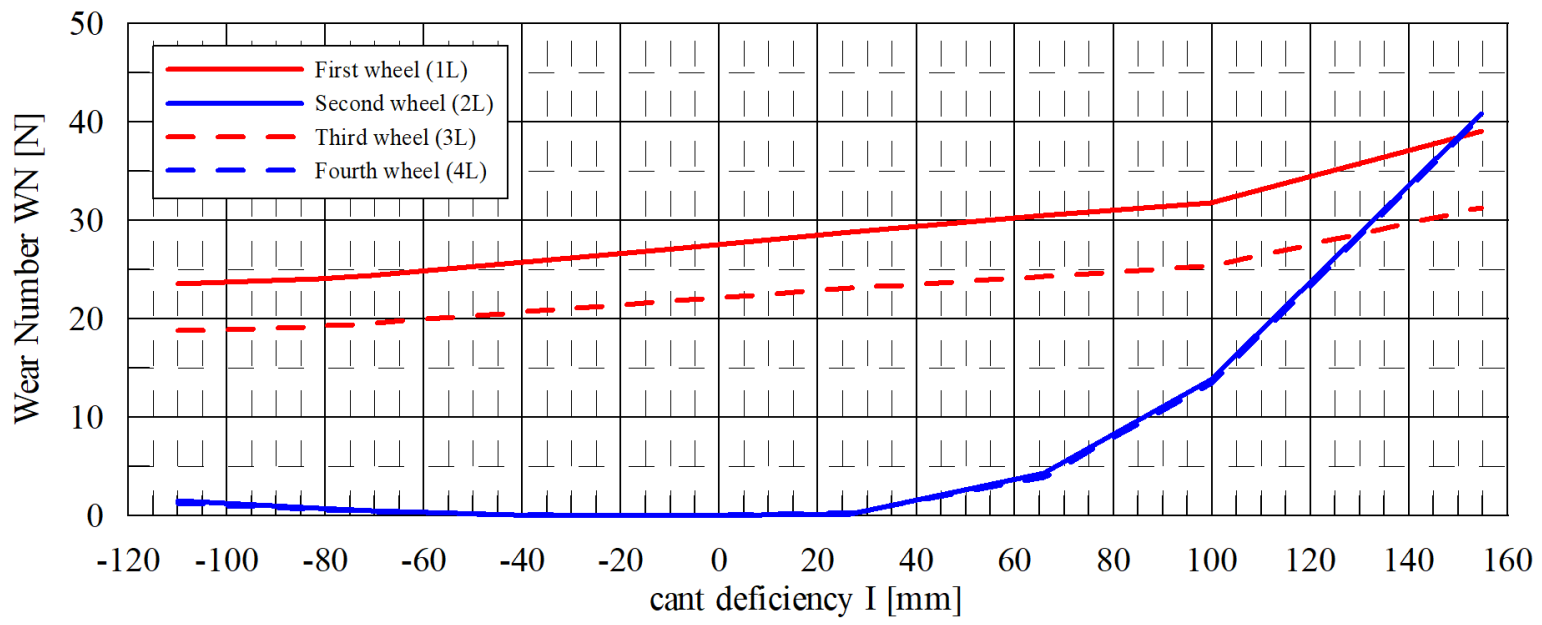

FiguRE 5. Dependence of the Wear Number $W N$ values on all outer wheels of the vehicle on the cant deficiency $I$ at constant track parameters (cant, curve radius).

$I$ on the Wear Number $W N$. Negative values of cant deficiency represent the cant excess.

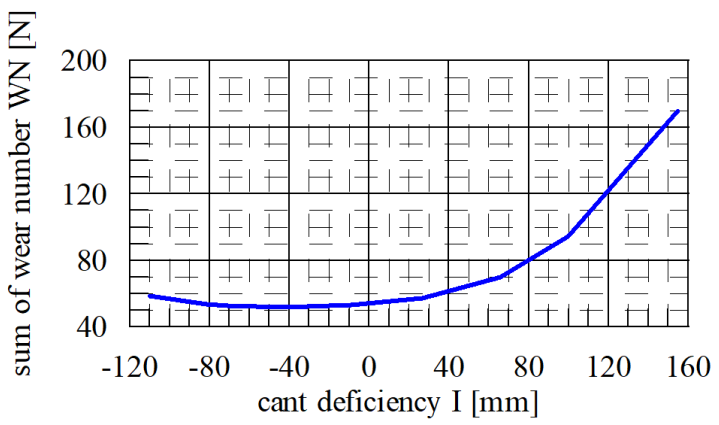

Figure 6. Dependence of the sum of the Wear Number $W N$ values of all vehicle wheels on cant deficiency $I$ at constant track parameters (cant, curve radius).

According to Figure 6, the sum of the Wear Number $W N$ values increases with increasing cant deficiency $I$. This applies to the positive values of cant deficiency. But for the cant excess values (negative values of cant deficiency), the Wear Number values are in a narrow range.

The situation where the values of the sum of the Wear Number were calculated for individual sides of railway vehicles is shown in Figure 7. The figure shows the sum of Wear Number of the four outer wheels (left side in Figure 1) and the four inner wheels (right side in Figure 1) of the railway vehicle. The chart in the figure shows that the values of the sum of Wear Number on the inner wheels are almost symmetrical around the value of the cant deficiency $I=0 \mathrm{~mm}$ with a polynomial character. It is obvious that the Wear Number values on the outer wheels are bigger than on the inner wheels.

The Wear Number values of the outer wheels for a positive values of the cant deficiency can be approximated using a quadratic function without constant parameter. Because the parameters of a quadratic function may vary depending on the vehicle/track conditions (vehicle construction, track irregularities), the type and shape of the function is important. The quadratic function is shown in Figure 7 by a gray dashed line.

According to this figure, the sum of the Wear Number on the outer wheels of the railway vehicle for the cant deficiency $I=110 \mathrm{~mm}$ is about twice as large as the sum of the Wear Number for the cant deficiency $I=0 \mathrm{~mm}$.

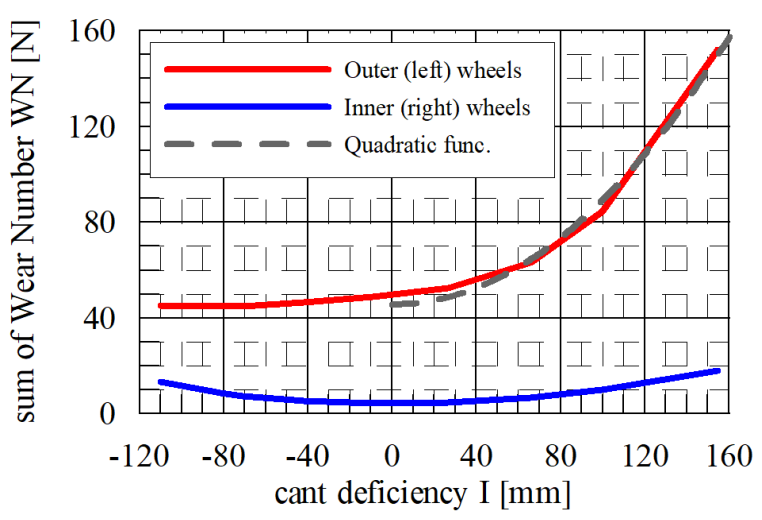

Figure 7. Dependence of the sum of the Wear Number $W N$ values on the inner and outer wheels of the vehicle on the cant deficiency $I$ at constant track parameters (cant, curve radius).

According to Figure 7, it is obvious that the main part of the Wear Number (specific friction work) is performed on the outer four wheels. That is the reason why this paper will further deal with the situation on the outer wheels of the railway vehicle, which is shown in Figure 5. The outer wheels of the front bogie (wheels 1L and 2L in Figure 1) are shown in solid lines and the outer wheels of the back bogie (wheels 3L and $4 \mathrm{~L}$ in Figure 1) are shown in dashed line.

As Figure 5 shows, for cant deficiency values around $I=0 \mathrm{~mm}$, the Wear Number values for the second $(2 \mathrm{~L})$ and fourth $(4 \mathrm{~L})$ wheels are close to zero. Then, as the cant deficiency value increases, the value of the 
Wear Number also increases with a progressive trend. However, the Wear Number value is about $37 \mathrm{~N}$ on the first wheel and about $22 \mathrm{~N}$ on the third wheel if the cant deficiency value is $I=0 \mathrm{~mm}$. For these wheels, the Wear Number values generally increase with increasing cant deficiency values.

The Wear Number values on the first (1L) and third (3L) wheels increase slower then the values on the second (2L) and fourth (4L) wheels. Finally, for the cant deficiency value of $150 \mathrm{~mm}$ (vehicle speed $344 \mathrm{~km} / \mathrm{h}$ ), the Wear Number values for the second and fourth wheels are higher than for the first wheel.

This is due to high centrifugal force that pushes the vehicle out of the curve. For normal high speed railway operation (the cant deficiency up to $100 \mathrm{~mm}$ ), the Wear Number value on the first outer wheel in the front bogie $(1 \mathrm{~L})$ is the highest value. This means that the largest specific friction work is performed on this wheel.

\subsubsection{INFLUENCE OF CURVE RADIUS}

In another case of the simulation scenario, the cant deficiency value is constant $I=100 \mathrm{~mm}$. This cant deficiency value is the maximum possible cant deficiency value for a vehicle speed higher than $300 \mathrm{~km} / \mathrm{h}$ according to the TSI 2. This means that the vehicle speed $V$ changes with the curve radius $R$. The specific simulation conditions are descibed in Section 3.2.3.

For the first introduction of this scenario, the simple chart is shown in Figure 8. Dependence of the sum of the Wear Number $W N$ values of all vehicle wheels on the curve radius $R$ is shown under the constant cant $D$ and cant deficiency $I$ conditions. The radius range of the curve from $3800 \mathrm{~m}$ to $5000 \mathrm{~m}$ corresponds to the range of vehicle speed from $300.3 \mathrm{~km} / \mathrm{h}$ to $344.5 \mathrm{~km} / \mathrm{h}$. It is obvious that the value of the sum of the Wear Number increases as the value of the curve radius decreases. This trend is also evident in methodology 4] which is focused on the conventional railway operation, so there is the range of the curve radius from $250 \mathrm{~m}$ to $1200 \mathrm{~m}$ and the values of Wear Number are much bigger depending on the smaller radius of the curve.

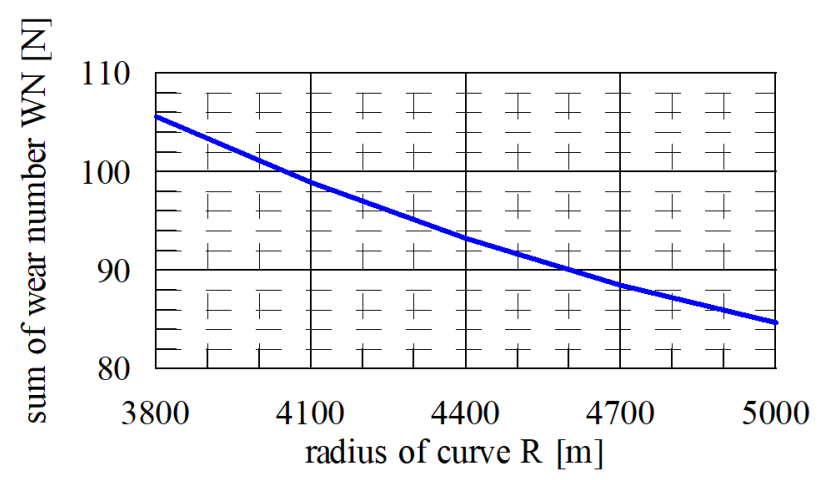

Figure 8. Dependence of the sum of the Wear Number $W N$ values of all vehicle wheels on the curve radius $R$ at constant value of cant and cant deficiency.
For a better view of this situation, the sum of the Wear Number values on all outer wheels (left side in Figure 1) and inner wheels (left side in Figure 1) of the vehicle is shown in Figure 9. The sum of the Wear Number on the inner wheels is approximately equal to $10 \mathrm{~N}$ for the whole range of curve radii. The main part of the specific friction work is performed in the contacts of the outer wheels with rail as Figure 9 shows. For the curve radius $R=5000 \mathrm{~m}$, the value of the sum of the Wear Number is $75 \mathrm{~N}$, then the value increases to $95 \mathrm{~N}$ for the curve radius $R=3800 \mathrm{~m}$. This means that it is necessary to be interested in the Wear Number values on the outer wheels.

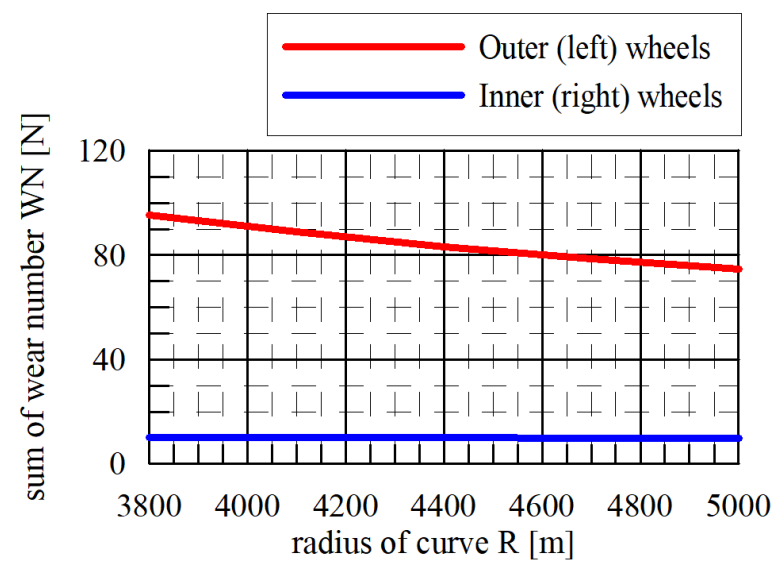

Figure 9. Dependence of the sum of the Wear Number $W N$ values on the inner and outer wheels of the vehicle on the curve radius $R$ at constant value of cant and cant deficiency.

Further analysis of the Wear Number on each outer wheel (wheels 1L, 2L, 3L, 4L according to Figure 1) is shown in Figure 10.

According to Figure 10, the largest specific friction work is performed on the first outer wheel (1L) of the vehicle. The values of the Wear Number on first outer wheel increase from $25 \mathrm{~N}$ up to $39 \mathrm{~N}$ for the range of the curve radius from $5000 \mathrm{~m}$ to $3800 \mathrm{~m}$. In context to these values, it can be assumed that the head checking rail defect will occur [4]. The Wear Number values on the third outer wheel (3L) have a similar trend as the first outer wheel, but the values are smaller.

The Wear Number values on the second outer wheels of both bogies $(2 \mathrm{~L}, 4 \mathrm{~L})$ are very similar and the Wear Number value increases as the radius of the curve increases. In this scenario, the centrifugal forces have the same value for each simulation. Thus, the trends of the Wear Number values are caused by the values of the angle of attack, which increase with decreasing values of the radius of the curve.

The absolute values of the Wear Number depend on other vehicle parameters and track conditions, but it can be assumed that the trends of the graph curves will be the same. 


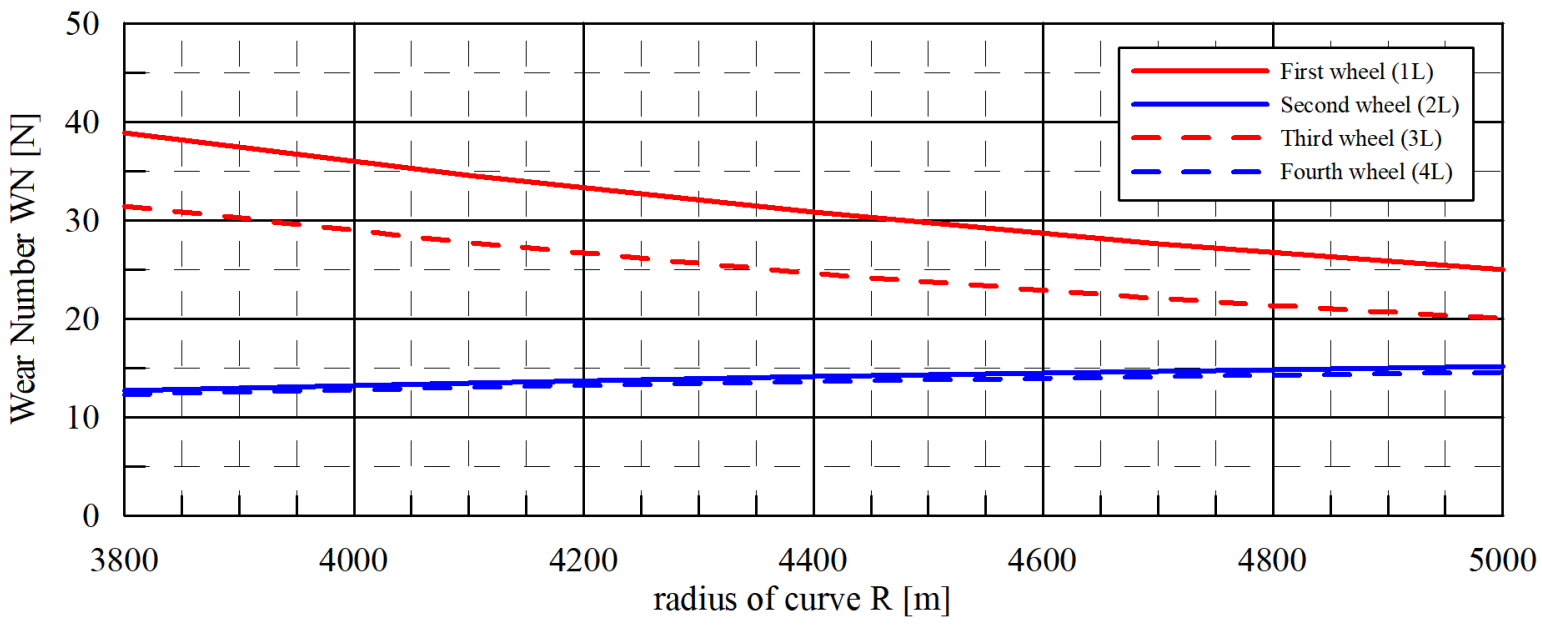

FiguRE 10. Dependence of the Wear Number $W N$ values of all outer wheels of the vehicle on the curve radius $R$ at constant value of cant $D$ and cant deficiency $I$.

\subsubsection{INFLUENCE OF SPECIFIC CONDITIONS AROUND THE SPEED LIMIT OF $300 \mathrm{KM} / \mathrm{H}$}

The specific conditions of this scenario are defined in Section 3.2.4. This scenario of multi-body simulations shows what happens at the vehicle speed $V=300$ $\mathrm{km} / \mathrm{h}$. The maximum permissible value of the cant deficiency changes abruptly from $153 \mathrm{~mm}$ to $100 \mathrm{~mm}$ at this vehicle speed.

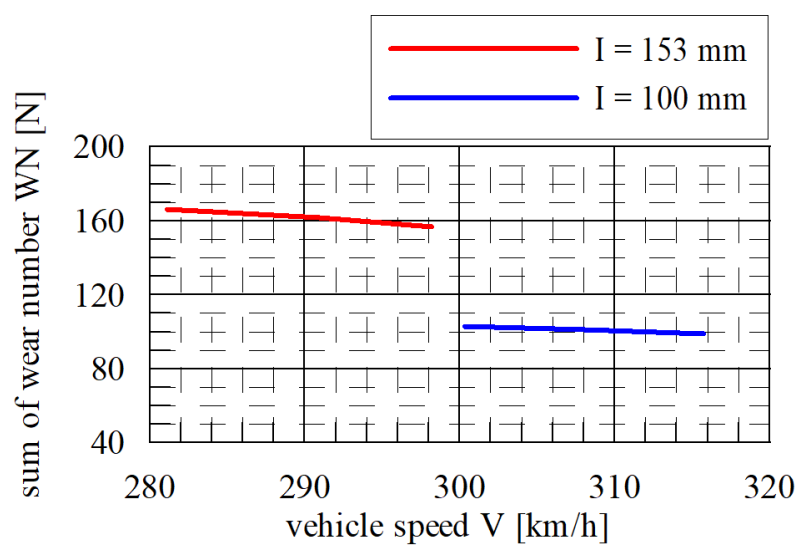

Figure 11. Dependence of the sum of the Wear Number $W N$ values of all wheels of the vehicle on the vehicle speed $V$ with the change of the cant deficiency value from $153 \mathrm{~mm}$ to $100 \mathrm{~mm}$.

The results of the multi-body simulations of this scenario are shown in Figure 11. The figure shows the dependence of the sum of the Wear Number $W N$ of all wheels on vehicle speed $V$. For vehicle speeds below $300 \mathrm{~km} / \mathrm{h}$, the cant deficiency is $153 \mathrm{~mm}$. For vehicle speeds above $300 \mathrm{~km} / \mathrm{h}$, the cant deficiency is $100 \mathrm{~mm}$. The radius of the curve varies according to the values of vehicle speed and cant deficiency.

According to Figure 11 it is obvious that the Wear Number values for vehicle speed below $300 \mathrm{~km} / \mathrm{h}$ are greater than the values for vehicle speed above 300 $\mathrm{km} / \mathrm{h}$ under the conditions of the maximum value of cant deficiency. For the high speed railway operation with a maximum value of cant deficiency, a vehicle speed greater than $300 \mathrm{~km} / \mathrm{h}$ is more advantageous in terms of specific friction work and track damage. However, larger radii of curve are required.

\section{Conclusions}

After comparing some methodologies for the vehicle/track interaction evaluation for conventional railway operation with the vehicle/track interaction under the conditions of high speed railway operation, it's obvious that the conditions and parameters of high speed railway operation are different from conventional operation.

When a high-speed vehicle runs on a straight track, the damaging effect increases as a result of an increase of the dynamic wheel force, which progressively depends on the vehicle speed.

A large radii of curve are required for high speed railway operation. This means that the Wear Number values are relatively small in compared to conventional operation and it can be assumed that the rail wear in the curve will be less intense than in conventional railway operation. But with increasing vehicle speed and cant deficiency, the values of Wear Number increase very quickly, as does the specific friction work in wheel/rail contact.

This paper primary shows trends of the dynamic vertical wheel force $Q$ and the Wear Number $W N$ values under the specific conditions of high speed railway operation and parameters of multi-body simulations, which are used for evaluation of vehicle/track interaction. The absolute values of these characteristics depend on the design of the railway vehicle and, of course, on the parameters and conditions of the track.

\section{ACKNOWLEDGEMENTS}

This work was supported by the scientific research project of the University of Pardubice No. SGS_2020_009. 


\section{REFERENCES}

[1] British Railway Board. Permissible track forces for railway vehicles. GM/TT0088, Issue 1, Revision A, 1993.

[2] Commision Regulation (EU) No 1299/2014 of 18 November 2014 on the technical specification for interoperability relating to the 'infrastructure' subsystem of the rail system in the European Union, 2014.

[3] T. Zhang, D. Huanyun. On the nonlinear dynamics of a high-speed railway vehicle with nonsmooth elements. Applied Mathematical Modelling 76:526-544, 2019.
[4] Base Price Wear in the train-path pricing system 2017 - Instruction for determining vehicle prices. Bern: Feredal Office of Transport, 2016.

[5] EN 14363:2016+A1:2018. Railway applications Testing and Simulation for the acceptance of running characteristics of railway vehicles - Running behaviour and stationary tests. Brusel: European Committee for Standardization, 2018. 